$\underset{\text { kedokteran gigi }}{\text { jurnal }}$

ISSN 2302-5271
Korespondensi:

Putri Ajri Mawadara

Program Studi Kedokteran Gigi Fakultas Kedokteran Universitas Sriwijaya

\section{Pengaruh penambahan hidroksiapatit dari cangkang telur ayam terhadapkekerasan permukaan GIC}

\author{
Putri Ajri Mawadara*, Martha Mozartha*, Trisnawaty \\ K* \\ *Program Studi Kedokteran Gigi Fakultas Kedokteran \\ Universitas Sriwijaya
}

\section{Abstrak}

Latar belakang: Hidrosiapatit (HA) merupakan biokeramik yang sangat biokompatibel,serta memiliki komposisi dan struktur kristal mirip dengan apatit di struktur gigi dan tulang manusia. Beberapa penelitian telah dilakukan untuk mengetahui pengaruh penambahan bubuk HA untuk memperbaiki sifat mekanis dari bahan restoratif gigi. Pada penelitian ini, HA disintesis dari cangkang telur ayam sebagai sumber kalsium untuk digunakan sebagai prekursor dalam sintesis HA dengan teknik presipitasi. Tujuan penelitian ini adalah untuk mengetahui pengaruh penambahan HA dari cangkang telur ayam terhadap kekerasan permukaan GIC (Fuji IX $\mathrm{GP}^{\circledR}$ ).Metode: Sampel dibagi menjadi 2 kelompok, yaitu kelompok GIC tanpa penambahan HA sebagai kelompok kontrol $(n=16)$ dan kelompok GIC dengan penambahan $5 \%$ HA sebagai kelompok uji $(n=16)$. Jumlah keseluruhan spesimen sebanyak 32 silinder berdiameter $5 \mathrm{~mm}$ dan tinggi $2 \mathrm{~mm}$. Kekerasan permukaan GIC diukur dengan vickers microhardness tester. Data dianalisis menggunakan uji $\mathrm{T}$ tidak berpasangan. Hasil: Rata-rata kekerasan permukaan GIC kelompok kontrol adalah $51,37 \pm 1,63 \mathrm{VHN}$ dan kelompok

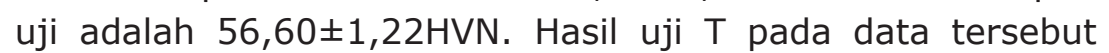
menunjukkan perbedaan signifikan antar kelompok $(p<0,05)$. Kesimpulan: Penambahan HA dari cangkang telur ayam pada bubuk GIC dapat meningkatkan kekerasan permukaan GIC.

Kata kunci: Hidroksiapatit, GIC, kekerasan permukaan 
Putri Ajri Mawadara: Pengaruh penambahan hidroksiapatit dari cangkang telur ayam .

\begin{abstract}
Hydroxyapatite (HA) is a bioceramic with excellentbiocompatible properties, and composition and crystal structure similar to apatite in the human dental structure and skeletal system. A number of researchers have attempted to evaluate the effect of the addition of HA powders to increasemechanical properties of restorative dental materials. In this study, HA was synthesized using chicken eggshell as calcium source for synthesizing HA by using precipitation technique. The aim of this study was to determine the effect of incorporation of eggshell-derived HA on the surface hardness GIC (Fuji IX GP ${ }^{\circledR}$ ). Specimens were divided into two groups: group GIC without incorporation of HA as control group $(n=16)$ and group GIC with incorporation of $5 \% \mathrm{HA}$ as experimental group $(n=16)$. Total of specimens were 32 cylinders $5 \mathrm{~mm}$ diameter and $2 \mathrm{~mm}$ height. Surface hardness GIC was measured with vickers microhardness tester. Data wasanalyzed by unpaired T-test. The mean of surface hardness for GIC control group was $51.37 \pm 1,63 \mathrm{VHN}$ and the experimental group was $56.60 \pm 1,22 \mathrm{HVN}$. The results T-test showed a significant difference between groups $(p<0.05)$. It can be concluded thatincorporation of eggshell-derivedHA could increasesurface hardness of GIC.
\end{abstract}

Keywords: Hydroxyapatite, GIC, surface hardness

\section{Pendahuluan}

Perkembangan teknologi modern telah memperkenalkan material keramik dengan sifat kimia, fisik, dan mekanik yang sangat baik untuk digunakan dalam berbagai aplikasi biomedis. ${ }^{1}$ Hidroksiapatit (HA) merupakan biokeramik yang sangat biokompatibel, serta memiliki komposisi dan struktur kristal mirip apatit di struktur gigi dan tulang manusia. ${ }^{2}$ Hidroksiapatit $\left(\mathrm{Ca}_{10}\left(\mathrm{PO}_{4}\right)_{6}(\mathrm{OH})_{2}\right)$ dapat disintesis dari bahan sintetis yaitu dengan menggunakan larutan kimia atau bahan alami seperti sisik ikan, tulang ikan, tulang sapi, cangkang telur, dan lain-lain. ${ }^{3,4}$

Cangkang telur ayam dapat dimanfaatkan sebagai sumber kalsium untuk digunakan sebagai prekursor dalam sintesis HA karena mengandung $94 \% \mathrm{CaCO}_{3}$ (kalsium karbonat). ${ }^{1}$ Menurut data dari Badan Pusat Data dan Sistem Informasi Pertanian tahun 2015, produksi telur ayam pada tahun
2014 sebesar 1.246 .000 ton per tahun dan $11 \%$ dari berat telur tersebut merupakan cangkang telur. Dengan demikian, sebanyak 137.060 ton limbah cangkang telur dihasilkan di seluruh Indonesia dalam setahun. ${ }^{5}$

Beberapa metode yang dapat digunakan untuk mensintesis HA dari bahan alami di antaranya metode presipitasi, solgel, hidrotermal, dan lain-lain. Metode presipitasi merupakan metode yang paling sering digunakan, karena sederhana, ekonomis, dan mudah.6,7 Menurut penelitian Saeed et,al., bubuk HA murni dapat dihasilkan dari sintesis cangkang telur ayam melalui metode presipitasi. ${ }^{8}$ Dalam bidang kedokteran gigi bubuk HA dari cangkang telur dapat digunakan untuk memperbaiki sifat mekanis dari bahan restorasi gigi, salah satunya adalah glass ionomer cement (GIC). ${ }^{9,10}$

Glass ionomer cement(GIC) merupakan material restoratif self-adhesive. 
GIC adalah semen berbasis air yang terbentuk melalui reaksi asam basaantara bubuk fluoroaluminosilikat kaca dan larutan kopolimer asam karboksilat. ${ }^{11} \mathrm{GICmemiliki}$ koefisien termal mirip gigi, berikatan secara kimia pada email dan dentin, serta biokompatibel. Namun, GIC bersifat rapuh (brittle) dan daya tahan terhadap keausan rendah,sehingga penggunaan GIC sebagai material restorasi terbatas pada kavitas yang tidak menerima tekanan besar. ${ }^{11,12}$

Penelitian mengenai penambahan HA pada bubuk GIC untuk memperbaiki sifat mekanisGICtelahdilakukan, sepertipenelitian Moshaverinia et, al.,yangmembuktikan bahwa penambahan 5\% HA pada bubuk GIC dapat meningkatkan kekuatan tekan, kekuatan tarik, dan kekuatan fleksural GIC. ${ }^{13}$ Rahman dkk. membandingkan penambahan HA-silika berukuran nano dengan berbagaikonsentrasi yang dibuatdengan teknik sol-gel pada bubuk GIC. Hasil penelitian tersebut menunjukkan nilai kekerasan yang paling tinggi padapenambahan 5\% HA-silika. Sementara penambahan HA-silika denganpersentase yang lebihtinggimenunjukkannilaikekerasan yang lebihrendah, namun masih lebih tinggi dari nilai kekerasan GIC tanpapenambahan HA-silika. ${ }^{14}$

Sifat kekerasan permukaansangat penting untukbahan restorasi gigi, termasuk juga GIC, karena berpengaruhpada kemudahanpenyelesaian akhir serta pemolesan bahan sertaketahanan bahan terhadapgoresan.Berdasarkan latar belakang yang telah diuraikan maka dilakukan penelitian ini,yang bertujuan untuk mengetahui pengaruh penambahan 5\% HA dari limbah cangkang telur ayam yang disintesis melalui metode presipitasi terhadap kekerasan permukaan GIC.

\section{Metode penelitian}

Penelitian ini adalah penelitian eksperimental laboratoris, dengan sampel penelitian yaituGIC Tipe II (Fuji IX $\mathrm{GP}^{\circledR}$ )yang dibuat menjadi spesimen berbentuk silinder dengan ukuran diameter $5 \mathrm{~mm}$ dan tinggi $2 \mathrm{~mm} .{ }^{14}$ Total keseluruhan sampel sebanyak 32 sampel yang dibagi menjadi 2 kelompok, yaitu kelompok $A(n=16)$ yang dibuat dari GIC tanpa penambahan hidroksiapatit (kelompok kontrol) dan kelompok B $(n=16)$ yang dibuat dari GIC dengan penambahan5 $\%$ hidroksiapatit yang berasal dari cangkang telur ayam (kelompok uji).

Cangkang telur ayam yang digunakan dalam penelitian ini berasal dari telur ayam ras dari peternakan Putra Perkasa Farm. Cangkang telur ayam sebanyak $200 \mathrm{~g}$ dicuci dan dibersihkan dengan aquabidesuntuk membersihkan cangkang telur dari selaput lendir dan kotoran, kemudiandikeringkan menggunakan oven dengan suhu $110^{\circ} \mathrm{C}$ selama 2 jam. ${ }^{15}$ Selanjutnya, cangkang telur dihaluskan dengan ball milling, kemudian diayak menggunakan pengayak ukuran 200mesh. ${ }^{16}$ Bubuk cangkangtelur tersebut dibakar menggunakan furnace pada suhu $1000^{\circ} \mathrm{C}$ selama 5 jam, yang bertujuan untuk mengeliminasi komponen organik dan logam lain selain kalsium ( $\mathrm{Ca}$ ) serta mengubah kalsium karbonat ( $\mathrm{CaCO} 3$ ) yang terkandung dalam cangkang telur ayam menjadi kalsium oksida ( $\mathrm{CaO}$ ) yang digunakan sebagai bahan pembuatan prekursor $\mathrm{Ca}$.

Tahapan selanjutnya adalah pembuatan larutan kalsium nitrat $\left(\mathrm{Ca}\left(\mathrm{NO}_{3}\right)_{2}\right)$ 10 M sebanyak $100 \mathrm{~mL}$ sebagai prekursor Ca. Bubuk $\mathrm{CaO}$ dari hasil pembakaran cangkang telur ayam ditimbang dengan timbangan digital sebanyak $56 \mathrm{~g}$ sesuai dengan perhitungan stoikiometri, kemudian dilarutkan dengan larutan asam nitrat $\left(\mathrm{HNO}_{3}\right)$ 68\% sebanyak $81 \mathrm{ml}$. Akuabides ditambahkan sebanyak $19 \mathrm{ml}$ hingga volume total menjadi $100 \mathrm{ml}$, dan diaduk dengan pengaduk magnetik agar suspensi homogen. Selanjutnya dibuat larutan asam fosfat $\left(\mathrm{H}_{3} \mathrm{PO}_{4} 6 \mathrm{M}\right.$ sebanyak $100 \mathrm{~mL}$ yang merupakan prekursor fosfat. Larutan $\mathrm{H}_{3} \mathrm{PO}_{4}$ konsentrasi $85 \%$ diukur sebanyak 28,5 $\mathrm{ml}$ dimasukkan kedalam gelas ukur sesuai dengan perhitungan stoikiometri kemudian dilarutkan dengan aquabides sebanyak 71,5 $\mathrm{ml}$ hingga volume total menjadi $100 \mathrm{ml}$ dan diaduk hingga larutan homogen.

Sintesis HA dengan metode presipitasi dilakukan dengan meneteskan larutan 
Putri Ajri Mawadara: Pengaruh penambahan hidroksiapatit dari cangkang telur ayam .

$\mathrm{H}_{3} \mathrm{PO}_{4} 100 \mathrm{ml}$ dengan menggunakan buret kedalam tabung erlemeyer yang berisi larutan $\mathrm{Ca}\left(\mathrm{NO}_{3}\right)_{2} 100 \mathrm{ml}^{7}$ lalu dipanaskan. Pemanasan diatur pada suhu $40^{\circ} \mathrm{C}$ (dijaga konstan) dengan kecepatan pengadukan $300 \mathrm{rpm}$ dan pengadukan tetap dilanjutkan tanpa pemanasan selama 30 menit setelah larutan fosfat habis direaksikan ${ }^{17} . \mathrm{pH}$ larutan dijaga tetappada pH 10 dengan menambahkan ammonium hidroksida $\left(\mathrm{NH}_{4} \mathrm{OH}\right)^{17}$. Kemudian dilakukan aging selama 24 dengan dimasukkan kedalam inkubator. Presipitat yang terbentuk kemudian disaring menggunakan kertas saring whatman 42, Ialu dicuci dengan aquabides untuk menghilangkan produk samping yaitu amonium nitrat $\left(\mathrm{NH}_{4} \mathrm{NO}_{3}\right) \cdot{ }^{17}$ Presipitat yang telah disaring kemudian dikeringkan dengan oven pada suhu $110^{\circ} \mathrm{C}$ selama 5 jam. ${ }^{15}$ Kemudian dilakukan sintering pada presipitat kering dengan cara dimasukkan ke dalam furnace pada temperatur $900^{\circ} \mathrm{C}$ selama 5 jam untuk meningkatkan derajat kristalinitasnya. ${ }^{2}$ Reaksi yang terjadi adalah sebagai berikut:

$10 \mathrm{Ca}\left(\mathrm{NO}_{3}\right)_{2}+6 \mathrm{H}_{3} \mathrm{PO}_{4}+20 \mathrm{NH}_{4} \mathrm{OHà} \mathrm{Ca}{ }_{10}\left(\mathrm{PO}_{4}\right)_{6}(\mathrm{OH})_{2}+20 \mathrm{NH}_{4} \mathrm{NO}_{3}+18 \mathrm{H}_{2} \mathrm{O}$

Karakteristik produk partikel hidroksiapatit yang dihasilkan dilakukan dengan menggunakan alat uji XRD ( $X$-Ray Diffraction) untuk mengetahui komposisi senyawa yang terbentuk. Puncak-puncak difraksi yang didapat kemudian dicocokkan dengan standar difraksi sinar-X dalam Joint Committee on Powder Diffraction Standards (JCPDS). Berdasarkan JCPDS 9-432, tiga puncak tertinggi hidroksiapatit memiliki nilai hkl: 211, 112, dan 300.

Berikutnya dilakukan pembuatan spesimen GIC. Untukspesimen pada kelompok A, GIC dimanipulasi sesuai dengan petunjuk pabrik dengan rasio 3,6g bubuk dan $1 \mathrm{~g}$ liquid GIC. Massa homogen dimasukkan ke dalam cetakan berbentuk silinder (diameter $5 \mathrm{~mm}$, tinggi $2 \mathrm{~mm}$ ). Permukaan adonan ditutup dengan celuloid stripdan diberikan beban $0,5 \mathrm{~kg}$. Setelah massa mengeras, celluloid stripdilepas dan spesimen dikeluarkan dari cetakan. Spesimen pada kelompok B dibuat dengan cara yang sama, namun bubuk GIC yang dipakai adalah sebanyak 3,4 gdengan penambahan $0,2 \mathrm{~g}$ hidroksiapatit. Bubuk GIC dan hidroksiapatit dicampur di dalam tabung erlenmeyer menggunakan shaker selama 15 detik. Setelah itu bubuk GIC dengan penambahan HA dimanipulasi dengan likuid sesuai petunjuk pabrik seperti di atas.

Pengukuran kekerasan permukaan spesimen GIC dilakukan dengan menggunakan vickers microhardness testerdi Laboratorium Polsri Palembang. Setiap spesimen diuji kekerasan pada 3 titik indentasi di tempat yang berbeda dan panjang diagonal ( $\mathrm{Da}, \mathrm{Db}, \mathrm{Dc})$ dari 3 titik indentasi diambil rata-ratanya kemudian dimasukkan ke dalam rumussebagai berikut:

$$
\mathrm{VHN}=1854.4 \mathrm{P} / \mathrm{d}^{2}
$$

Keterangan:

$\mathrm{VHN}=$ Angka kekerasan vickers

$\mathrm{P}=$ Beban $(\mathrm{kg})$

$\mathrm{d}=$ Rata-rata diagonal indentasi $(\mathrm{mm})$

Data yang didapat diolah dan dianalisa secara statistik menggunakan uji T tidak berpasangan.

\section{Hasil penelitian}

Penelitian ini didahului dengan pembuatan bubuk HA dari cangkang telur ayam dengan metode presipitasi yang dilakukan di Laboratorium Rekayasa Bioproses Jurusan Teknik Kimia Politeknik Negeri Sriwijaya Palembang. Bubuk HA selanjutnya dikarakterisasi menggunakan $X$-Ray Diffraction (XRD) di Laboratorium Terpadu Fisika UIN Syarif Hidayatullah Jakarta untuk mengetahui komposisi senyawa bubuk yang terbentuk dari metode presipitasi.

Hasil XRD menunjukkan puncak-puncak tertinggi pada difraktogram dengan sudut (20) 31.809, 32.228, dan 32.949 memiliki nilai hkl 211, 112, dan 300 (Gambar 1). Data tersebut cocok dengan data standarThe Joint Committee on Powder Diffraction Standards(JCPDS) (9-432) sehingga dapat dipastikan bahwa bubuk yang diperoleh dari metode presipitasi yang telah dilakukan adalah HA. 


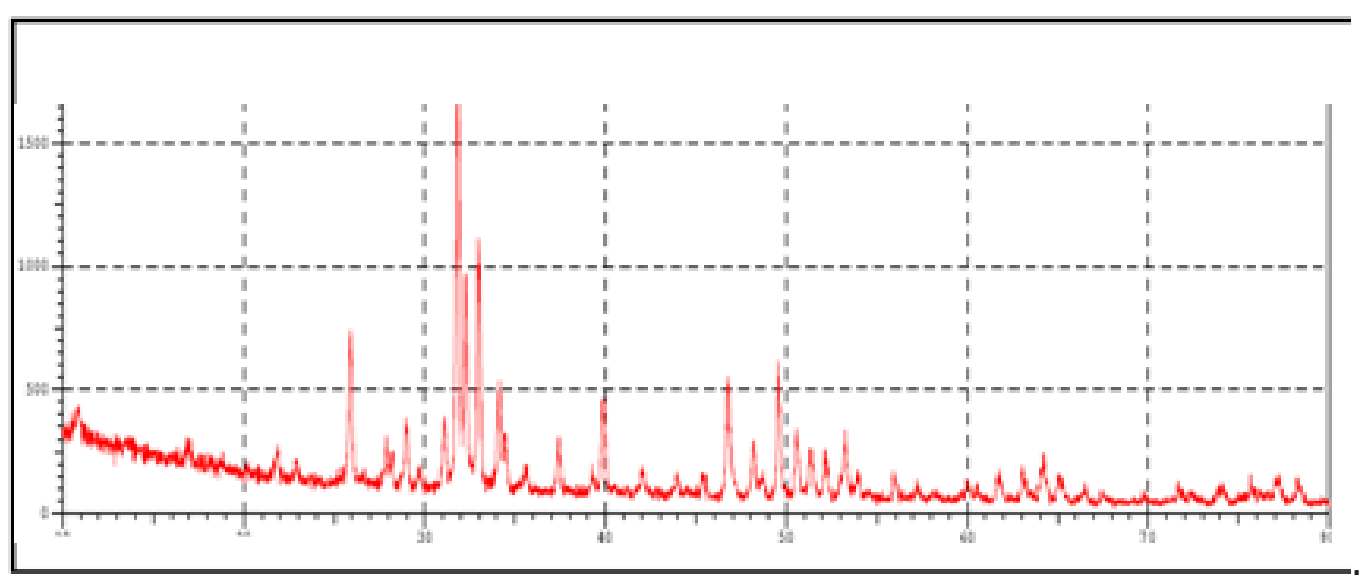

Keterangan: sumbu $x$ : 2-theta (sudut penembakan sinar-x terhadap sampel), sumbu y : counts (intensitas cahaya yang diserap oleh sampel)

\section{Gambar 1. Difraktogram Hasil Analisa XRD}

Tabel 1. Perbedaan nilai rata-rata kekerasan permukaan GIC antara kelompok kontrol dan kelompok uji

\begin{tabular}{lrrrc}
\hline Kelompok & $\mathrm{N}$ & \multicolumn{1}{c}{ Mean \pm SD } & Mean Difference & \multicolumn{1}{c}{ p.value } \\
\hline Kelompok Kontrol & 16 & $51,37 \pm 1,63$ & $-5,225$ & $0,000 *$ \\
Kelompok Uji & 16 & $56,60 \pm 1,22$ & $-5,225$ & $0,000 *$ \\
\hline
\end{tabular}

\section{Keterangan :}

*: menunjukkan adanya perbedaan yang signifikan pada uji T tidak berpasangan $(\mathrm{p}<0.05)$

Hasil uji kekerasan permukaan dengan menggunakan Vickers Microhardness Tester ditunjukkan pada Tabel 1 . Nilai rata-rata kekerasan permukaan GIC pada kelompok uji (GIC dengan penambahan 5\% HA)lebih tinggi dibandingkan kelompok kontrol. Pada Tabel 1 juga dapat dilihat hasil uji T tidak berpasangan yangmenunjukkan bahwa perbedaan kekerasan permukaan GIC tersebut signifikan $(p<0,05)$.

\section{Pembahasan}

Glass ionomer cement (GIC) merupakan material restoratif self-adhesive dengan sifat mekanik yang rendah sehingga penggunaannya terbatas pada kavitas yang tidak menerima tekanan besar. ${ }^{11}$ Beberapa penelitian telah dilakukan untuk meningkatkan sifat mekanik GIC, salah satunya dengan cara penambahan hidroksiapatit pada bubuk GIC. ${ }^{2,13,14}$

Hidroksiapatit (HA) merupakan biokeramik golongan kalsium fosfat, yang merupakan komponen utama dari enamel gigi. ${ }^{13}$ Hidroksiapatit dapat disintesis dari bahan alami dengan berbagai metode, salah satunya dengan metode presipitasi. ${ }^{7}$ pada penelitian ini, sintesis HA dilakukan dengan metode presipitasi dengan menggunakan prekursor kalsium dari cangkang telur ayam dan prekursor fosfat dari $\mathrm{H}_{3} \mathrm{PO}_{4}{ }^{10}$ Bubuk HA yang dihasilkan dianalisa dengan uji XRD untuk mengetahui komposisi senyawa yangterkandungpada bubuk tersebut. Hasil uji XRD cocok dengan data standar JCPDS (9-432) sehingga dapat dipastikan bahwa bubuk tersebut adalah HA.

Selain senyawa $H A$, terbentuk juga senyawa trikalsium fosfat (TCP) dengan nilai hkl 214, 0210, dan 220 pada sudut (20) 27.859, 31.059, dan 34.420. ТCP dapat terbentuk akibat adanya pemanasan bubuk HA pada suhu di atas $600^{\circ} \mathrm{C} .{ }^{18}$ Pada penelitian ini dilakukan sintering bubuk HA pada suhu $900^{\circ} \mathrm{C}$ sehingga mengakibatkan 
Putri Ajri Mawadara: Pengaruh penambahan hidroksiapatit dari cangkang telur ayam .

terbentuknya TCP yang terlihat dalam analisis XRD. Menurut penelitian Wardani dkk., HA terdekomposisi menjadi fasa TCP pada suhu $700^{\circ} \mathrm{C}$ dan terkristalisasi sempurna di atas suhu $900^{\circ} \mathrm{C} .{ }^{19}$ Trikalsium fosfat adalah biomaterial yang berpotensi tinggi untuk aplikasi biologis karena merupakan salah satu mineral kalsium fosfat yang terdapat di dalam enamel gigi dan tulang. Penelitian terdahulu telah melakukan penambahan partikel TCP pada GIC, yang memperlihatkan bahwapenambahan $15 \%$ nanopartikel $\beta$-TCP pada GIC dapat meningkatkan sifat mekanik GIC. ${ }^{20}$ Penambahan TCP juga meningkatkan remineralisasi enamel secara signifikan tanpa mempengaruhi sifat mekanik fissure sealant. ${ }^{21}$

Hasil penelitian ini (Tabel 1) menunjukkan bahwa terdapat perbedaan yang signifikan $(p<0,05)$ antara nilai ratarata kekerasan permukaan kelompok GIC konvensional dan kelompok GIC dengan penambahan $5 \%$ HA.Hasil tersebut serupa dengan hasil penelitian Rahmanet, al., ${ }^{14}$ yang menunjukkan penambahan 5\% HA dari bahan kimia meningkatkan nilai kekerasan permukaan GIC.Pada saat bubuk GIC yang mengandung HA bercampur dengan likuid GIC, ion kalsium dalam HA akan ikut terlibat dalam reaksi asam basa dengan likuid sehingga setelah fase pembentukan gel terbentuk lebih banyak jembatan garam dan membentuk struktur cross-linking. ${ }^{22}$

Shiekh dkk melakukan penambahan partikel HA-silika berukuran nano dari bahan kimia yang disintesis dengan metode solgel ke dalam bubuk GIC. Karakterisasi partikel HA menggunakan TEM dan SEM mengungkapkan bahwa morfologi HA-silika yang dihasilkan merupakan campuran dari partikel silika berbentuk bulat dan partikel HA yang berbentuk seperti batang. Dari pemeriksaan tersebut juga dipastikan bahwa bubuk nanokomposit HA-silika tertanam dalam sempurna dalam matriks GIC, dan mengisi ruang-ruang kosong antara partikel GIC sehingga dapat meningkatkan sifat mekanis GIC. ${ }^{23}$ Selain bentuk partikel, ukuran dan area permukaan partikel HA juga menjadi faktor penting yang mempengaruhi sifat mekanis GIC. ${ }^{2}$ Pada penelitian ini tidak dilakukan karakterisasi ukuran, bentuk, dan area permukaan partikel HA yang dihasilkan, sehingga perlu penelitian lebih lanjut untuk mengetahui mekanisme penguatan partikel HA dari cangkang telur ayam terhadap GIC.

\section{Daftar Pustaka}

1. Rivera, EM. Hydroxyapatite-based materials: synthesis and characterization. In: Reza FR, editor. Biomedical Engineering-frontiers and challenges. Croatia: Intech; 2011. p. 75-88.

2. Arita $K$, Yamamoto $A$, Shinonaga $Y$, Harada K, Abe Y, Nakagawa K, et al. Hydroxyapatite particle characteristics influence the enhancement of the mechanical and chemical properties of conventional restorative glass ionomer cement. Dental Material Journal. 2011; 30(5): 672-683.

3. Sudip M, Biswanath M, Dey A, Mukhopadhyay SS. Studies on processing and characterization of hydroxyapatite biomaterials from different bio wastes. Journal of Minerals and Material Characterization and Engineering. 2012; 11(1): 55-67.

4. Bin MI, Dara A, Sontang M, Zuha R, Marlini AN. Fish bone waste utilization program for hydroxyapatite product : a case study of knowledge transfer from a university to coastal communities. Journal of Environmental Research and Development. 2013; 7(3): 1274-1281.

5. Pusat Data dan Sistem Informasi Pertanian. Statistik konsumsi pangan tahun 2015. Jakarta. 2015; 83.

6. Nayak Ak. Hydroxyapatite synthesis methodologies: An overview. ChemTech Res. 2010; 2(2): 903-907.

7. Sadat-Shojai M, Khorasani MT, Dinpanah-Khoshdargi E, Jamshidi A. Synthesis methods for nanosized hydroxyapatite with diverse structures. Acta biomaterialia. 2013; 9(8): 7591621.

8. Saeed AM, Hassan RA, Tahjeel KM. Synthesis of calcium hydroxyapatite 
powder from hen's eggshell. Iraqi Journal of Physics. 2011; 9(16): 24-8.

9. Al-Maamori $\mathrm{MH}$, Awad $\mathrm{SH}$, Hussein AK. Mechanical properties and liner shrinkage of resin reinforced with micro hydrokxyapatite for dental restoration. International Journal of Current Engineering and Technology. 2014; 4(3): 2151-2154.

10. Mozartha M, Praziandithe M, Sulistiawati. Pengaruh penambahan hidroksiapatit dari cangkang telur terhadap kekuatan tekan glass ionomer cement. FKG. Univ. Baiturrahman: Jurnal B-dent. 2015; 2(1): 75-81.

11. Sakaguchi RL, Powers JM. Craigs restorative dental material thirteenth edition. Elsevier: Mosby; 2012. 152-182.

12. McCabe JF, Walls AW. Applied dental materials ninth edition. UK: Blackwell Munksgaard; 2008. 245-258.

13. Moshaverinia A, Ansari S, Moshaverinia M, Roohpour N, Darr JA, Rehman I. Effects of incorporation of hydroxyapatite and fluoroapatite nanobioceramics into conventional glass ionomer cement (GIC). Acta biomaterialia. 2008; 4(2): 432-40.

14. Rahman IA, Masudi SM, Luddin N, Shiekh RA. One-pot synthesis of hydroxyapatitesilica nanopowder composite for hardness enhancement of glass ionomer cement (GIC). Indian Academy of Sciences. 2014; 37(2): 213-219.

15. Andika R, Fadli A, Irdoni HS. Pengaruh waktu ageing dan kecepatan pengadukan pada sintesis hidroksiapatit dari cangkang telur dengan metode presipitasi. Riau: JOM FTEKNIK. 2015; 2(1): 1-8.
16. Mahreni, Sulistyowati E, Sampe S, Chandra W. Pembuatan hidroksiapatit dari kulit telur. Yogyakarta. 2012; 1-5.

17. Wardani NS, Fadli A, Irdoni. Sintesis Hidroksiapatit dari cangkang telur dengan metode presipitasi. Riau: JOM FTEKNIK. 2015; 2(1): 1-6.

18. Mahreni, Sulistyowati E, Sampe S, Chandra W. Pembuatan hidroksiapatit dari kulit telur. Yogyakarta. 2012; 1-5.

19. Wardani NS, Fadli A, Irdoni. Sintesis Hidroksiapatit dari cangkang telur dengan metode presipitasi. Riau: JOM FTEKNIK. 2015; 2(1): 1-6.

20. Hong $Y W$, Kim JH, Lee $B H$, Lee $Y K$, Choi BJ, Lee $\mathrm{JH}$, et al. The Effect of nano-sized $\beta$-tricalcium phosphate on remineralization in glass ionomer dental luting cement. Key Eng Mater: Korea. 2008; 861-864.

21. Tavassoli HS, Atai M, Haghgoo R, Rahimian IS, Kameli $S$, Ahmaian $\mathrm{BF}$, et al. Comparison of various concentrations of tricalcium phosphate nanoparticles on mechanical properties and remineralization of fissure sealants. Original article: Iran. 2014; 11(4): 379388.

22. Yap AUJ, Pek YS, Kumar RA, Cheang $P_{\text {, }}$ Khor KA. Experimental studies on a new bioactive material: HAIonomer cements. Biomaterials: Singapore. 2002; 955-962.

23. Shiekh RA, Rahman IA, Masudi SM, Luddin N. Modification of glass ionomer cement by incorporating hydroxyapatitesilica nano-powder composite: Sol-gel synthesis and characterization. Ceramics international: Malaysia. 2014; 31653170 . 